\title{
Microgravimetric and GPR surveys for detection of unconsolidated zones in a levee
}

\author{
Monika Łój ${ }^{1,}{ }^{*}$, Sławomir Porzucek ${ }^{1}$, Tomisław Gołębiowski ${ }^{2}$ and Mark E. Everett ${ }^{3}$ \\ ${ }^{1}$ AGH University of Science and Technology, Cracow, Poland \\ ${ }^{2}$ Cracow University of Technology, Cracow, Poland \\ ${ }^{3}$ Texas A\&M University, College Station, USA
}

\begin{abstract}
Selected results of complex geophysical surveys carried out on the Vistula river flood levee in Cracow are herein presented. Two complementary geophysical methods were applied for detection of potential unconsolidated zones in the body of the levee, i.e. microgravimetry and ground-penetrating radar (GPR). The surveys were carried out in 2D mode, along a profile at the crown of the flood levee. Microgravimetric data reveal anomalies showing zones of decreased bulk density. These zones provide information about poor quality of the levee. The main anomaly was interpreted in a quantitative manner using gravity modelling. Non-standard GPR processing and visualization of radargrams were employed to better extract information concerning the distribution of unconsolidated zones. High resolution GPR surveys allow to outline such zones which was the basis for construction of the 2D model used in the gravimetric modelling. Integration of these two geophysical methods provided important information about the spatial variations of mass density in several unconsolidated zones within the body of the flood levee.
\end{abstract}

Keywords: microgravimetry, GPR, levee, gravity modelling, unconsolidated zones

\section{Introduction}

Levees are critical hydraulic structures in terms of protection of human life and security of real property. For this reason, it is important to keep them in the best possible geotechnical condition. The performance integrity of levees is usually determined by standard geotechnical surveys. However, such surveys provide only point wise information about the condition of levees, therefore it is essential to apply methods which can reveal the geotechnical condition in a spatially continuous manner. Geophysical techniques such as electrical resistivity tomography (ERT), induced polarization (IP), electromagnetic induction (EM) $[2,4,10]$ and ground-penetrating radar (GPR) $[3,5,6,11]$, are frequently used for this purpose. In addition, MASW method [12] and microgravimetry are increasingly being used to recognize the geotechnical condition of flood levee. Microgravimetry delivers information

\footnotetext{
* Corresponding author: mloj@agh.edu.pl
} 
about the bulk density distribution within a study area [7]. In the case of a levee, locations of reduced mass density can be identified. Additionally, this method allows to define the nearsurface geology and potentially find water seepage zones. In this paper we have applied microgravity together with the GPR method for assessment of geotechnical condition of selected flood levee.

\section{Geophysical surveys}

The geophysical surveys were carried out on the Vistula flood levee, between boreholes L89+782 and L90+090, as shown in Fig. 1. In 2014, this section of levee was designated for renovation due to its poor geotechnical condition. Our measurements were made along a $350 \mathrm{~m}$ long profile, located on the crown of the levee-crest axis (Fig. 1).

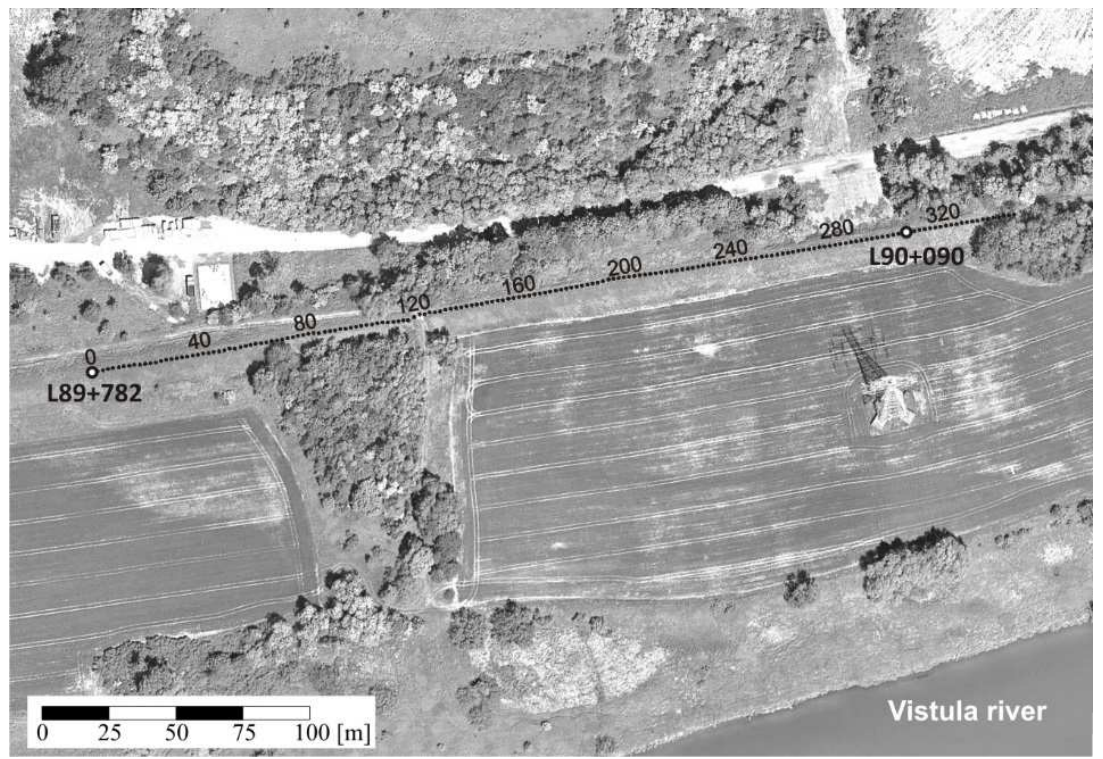

Fig. 1. Location of the profile for geophysical surveys.

In terms of geology, the study area is located within the Carpathian foredeep, which is filled with Miocene sediments. Within these sediments, the Vistula River has channelized its bed. The Vistula flood levees were constructed beginning at the end of the 19th century. These are the open levees which protect the surrounding private and industrial land and buildings against flood waters of the Vistula River.

Local raw materials i.e. sands, clays and gravels, as well as anthropogenic materials (ash, slags) were usually used during the original construction of the levee. These materials were not well sorted which means that there could be many heterogeneities within the levee structure.

As mentioned earlier, the geophysical profile passes between the two geotechnical boreholes L89+782 and L90+090 (Fig. 1). Geotechnical testing produced cross-sections (Fig. 2) which verify that the levee is made of various materials. In borehole L89+782, under a thin layer of fine sand with humus, there exists silt with cobble to depth $1.5 \mathrm{~m}$. Below them is clay to depth $2.9 \mathrm{~m}$. In the cross-section (Fig. 2, left), it appears that this part of the levee and its basement are composed of horizontal layers. In the other borehole L90+090 (Fig. 2 right), mainly silty clay to depth $3.8 \mathrm{~m}$ is found along with compact silty clay deeper to a depth $5.0 \mathrm{~m}$. In this cross-section (Fig. 2, right), it appears that the central part of the levee lies in a basin - the levee either fills a natural depression or this part of the levee subsided. 

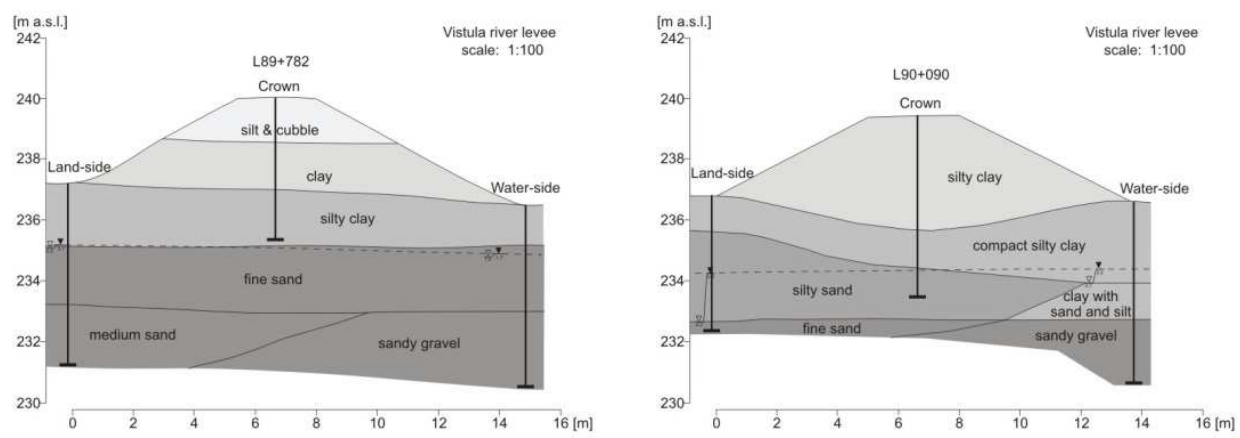

Fig. 2. Geotechnical cross-sections across boreholes: L89+782 (left) and L90+090 (right).

\subsection{Microgravimetric surveys}

Microgravimetric measurements were carried out at station spacing $2 \mathrm{~m}$ using the Scintrex CG-5 high-grade quartz gravimeter, which has automatic recording capabilities. The microgravimetric observations were repeated at many stations to calculate the mean square error of measurements, which amounted to $\pm 0.004 \mathrm{mGal}$. This value is in correspondence with the technical specifications of the gravimeter and confirmed that our observations were carried out to high precision. The data were used to calculate the Bouguer anomaly at each of the measurement stations, based on a presumed average bulk density $2 \mathrm{~g} \cdot \mathrm{cm}^{-3}$. In view of small changes in the station elevation along the profile, any error in the presumed density does not have a significant impact on the Bouguer anomaly.

The resulting Bouguer anomaly profile (Fig. 3) contains substantial small-scale variability. To try to reduce this variability, despite the small elevation changes from station to station, a terrain correction was calculated. The terrain-corrected Bouguer anomaly retains however much of the small-scale variability.

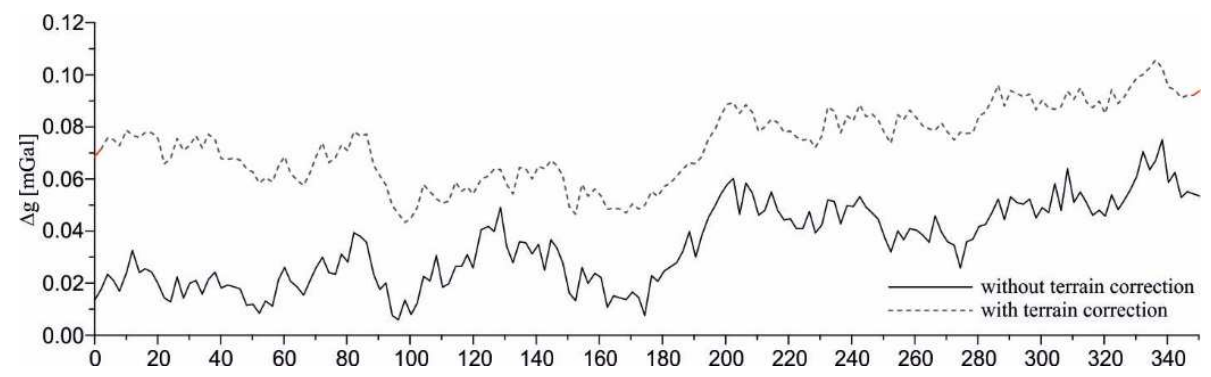

Fig. 3. Bouguer anomaly before and after terrain correction.

On this basis it could be assumed that the remaining small-scale variability comes from measurement errors and/or near-surface density changes within the uppermost layer, $1 \mathrm{~m}$ deep. In order to further reduce the variability, a low-pass Butterworth filter in the wavenumber domain with a cut-off wavelength of $20 \mathrm{~m}$ was applied. Comparison of the results before and after filter application confirmed that the cut-off parameter was chosen appropriately (Fig. 4). 


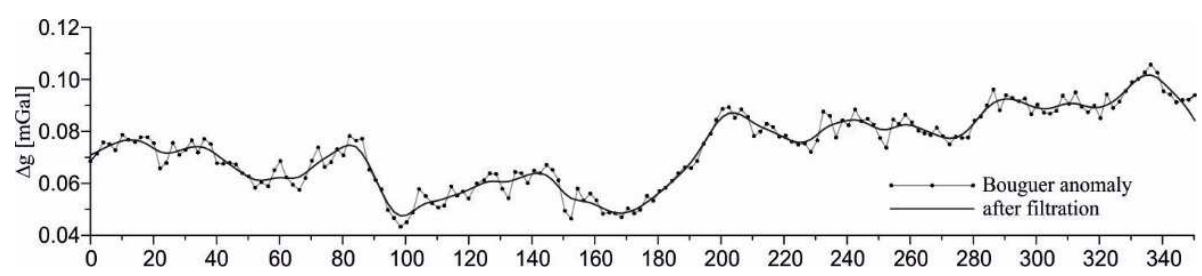

Fig. 4. Low-pass filter applied to Bouguer anomaly.

The filtered Bouguer anomaly shows a regional trend, reflected in the increase of the anomaly value in the direction of the profile. This trend was eliminated by subtracting a second degree polynomial approximation (Fig. 5).

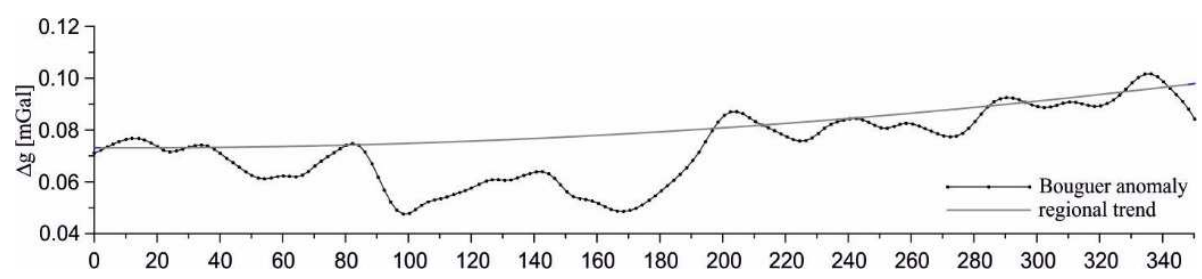

Fig. 5. Bouguer anomaly with the regional trend.

The residual anomaly, after the trend removal, is shown in Fig. 6. There are two significant negative residual anomalies; these are marked with the " $A$ " and " $B$ " symbols. Anomaly "B" is located between 90 and $190 \mathrm{~m}$ and has small amplitude $\sim 0.03 \mathrm{mGal}$. The shape of the anomaly shows that it is generated by an laterally extensive, shallow-buried zone of relatively low bulk density. It can also be seen that anomaly " $\mathrm{B}$ " is bimodal, with a central maximum flanking two minima, which indicates a denser area in the centre of the anomaly. The above-mentioned area is at the point of a local road crossing the levee.

A smaller region of decreased density located within the profile section between 45 and $75 \mathrm{~m}$ (anomaly "A") is also observed. The amplitude of this anomaly is $\sim 0.015 \mathrm{mGal}$. Other smaller residual anomalies with amplitudes below $0.01 \mathrm{mGal}$ correspond to small local changes in a bulk density. As shown below, some of these are partially visible in the GPR sections.

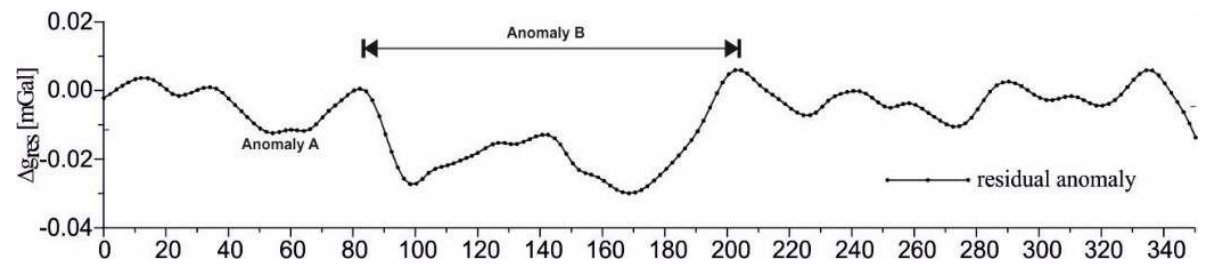

Fig. 6. Residual anomaly after trend removal.

\subsection{GPR surveys}

The GPR surveys were primarily designed for site reconnaissance and accordingly were carried out in a fast 2D mode, specifically as short-offset reflection profiling. The twochannel Swedish-made ProEx georadar (www.guidelinegeo.se) was used. The system enables the user to conduct simultaneous measurements using two different antennae. Taking into account the overall height of the levee and the necessity of resolving small-scale unconsolidated zones, a $500 \mathrm{MHz}$ antenna (Table 1) was connected to the first channel of GPR system. However, the body of the levee is composed of clay and silt, such that high attenuation and consequently low depth penetration is expected at this frequency Thus, an 
antenna with lower frequency $250 \mathrm{MHz}$ (Table 1) was connected to the second channel. Both antennae are bistatic and shielded and the standard orientation of Tx and Rx dipoles (i.e. copole orientation) was adopted during the measurements. Traces were recorded along the profile at spacing $\Delta x=0.02 \mathrm{~m}$ (for the $500 \mathrm{MHz}$ antenna) and $\Delta \mathrm{x}=0.05 \mathrm{~m}$ (for the $250 \mathrm{MHz}$ antenna). During the GPR surveys the stacking number varied between $4 \mathrm{x}$ and $32 \mathrm{x}$ in order to improve the signal/noise ratio.

The radargrams presented in the paper are shown in normalized form, i.e. with amplitudes (energies) normalized to the maximum amplitude (energy) of the direct air wave. For timedepth conversion a constant mean velocity $0.09 \mathrm{~m} / \mathrm{ns}$ is assumed; such velocity is appropriate for the mixture of silt and clay which comprises the body of the levee $[1,8,9]$.

In the first stage of data processing, radargrams were digitally processed with the use of the ReflexW program (www.sandeiergeo.de). The following standard procedures [12] were applied: time-zero correction, de-wow, DC correction, Butterworth filtering, 1D median filtering, application of gain function, background removal, stacking, $2 \mathrm{D}$ average procedure. The processed radargrams for $250 \mathrm{MHz}$ and $500 \mathrm{MHz}$ antennae, for different stacking numbers, are shown in Figs. 7-10.

Table 1. Penetration/resolution parameters of applied antennae [6].

\begin{tabular}{|c|c|c|}
\hline Central frequency & Max. depth penetration & Mean resolution \\
\hline $250 \mathrm{MHz}$ & $10 \mathrm{~m}$ & $0.1 \mathrm{~m}$ \\
\hline $500 \mathrm{MHz}$ & $5 \mathrm{~m}$ & $0.05 \mathrm{~m}$ \\
\hline
\end{tabular}

In Figs. 7-10, the reduction of the depth penetration of the electromagnetic wave in comparison with the maximum penetration (Table 1) of a given antenna, is caused by the high attenuation of clay (Fig. 2). In such situations, only those unconsolidated zones that are located near the top of the levee might be detected; thus a joint interpretation of GPR and microgravimetric data is possible only for this near-surface region.

Along the entire length of the profile (Figs. 7-10), a boundary at depth $\sim 1.0 \mathrm{~m}$ was recorded by the $250 \mathrm{MHz}$ and $500 \mathrm{MHz}$ antennae; this anomaly may be interpreted as the boundary between silt and clay (Fig. 2) or as an internal boundary in silt. In the near-surface zone (i.e. in silt), two main laterally disrupted regions may be distinguished in Figs. 7-10, i.e.: between $\mathrm{x}=0 \mathrm{~m}$ and $\mathrm{x}=125 \mathrm{~m}$, and from $\mathrm{x}=210 \mathrm{~m}$ to $\mathrm{x}=225 \mathrm{~m}$. It is interesting also to note that there are sometimes large differences in radargrams recorded for different stacking numbers, e.g.:

- in Fig. 7B, a continuous, horizontal and thin group of signals between $x=137 \mathrm{~m}$ and $\mathrm{x}=196 \mathrm{~m}$ is visible but in Fig. $8 \mathrm{~B}$ this group of signals is wide and interrupted,

- in Fig. 7C, a high-amplitude wide anomaly between $\mathrm{x}=247 \mathrm{~m}$ and $\mathrm{x}=283 \mathrm{~m}$ is recorded but in Fig. 8C, a thin anomaly is visible in this place,

- in Fig. 9B it is difficult to depict an anomaly between $x=210 \mathrm{~m}$ and $\mathrm{x}=225 \mathrm{~m}$ but in Fig. $10 \mathrm{~B}$ anomaly at this location is easily distinguished,

- in Figs. 7B and 8B reflections from trees were recorded, between $\mathrm{x}=168 \mathrm{~m}$ and $x=175 \mathrm{~m}$ and $\mathrm{x}=312 \mathrm{~m}$ and $\mathrm{x}=322 \mathrm{~m}$, but in Fig. 10C these reflections are not visible.

There are many more such examples in Figs. 7-10 but only a few selected differences are discussed here in order to show how the stacking number influences GPR recordings. 


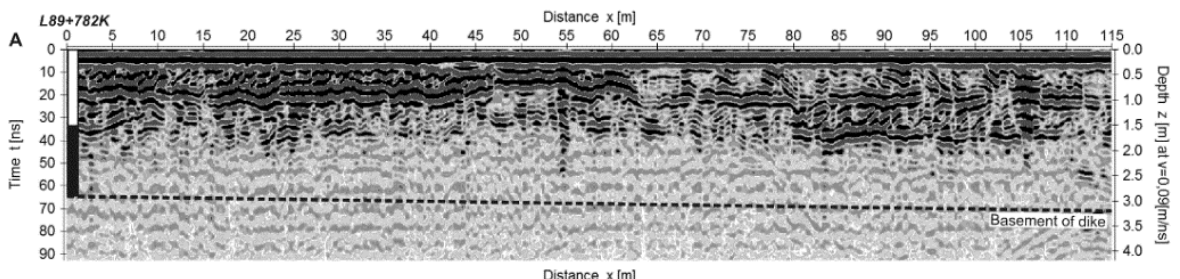

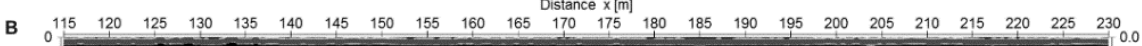

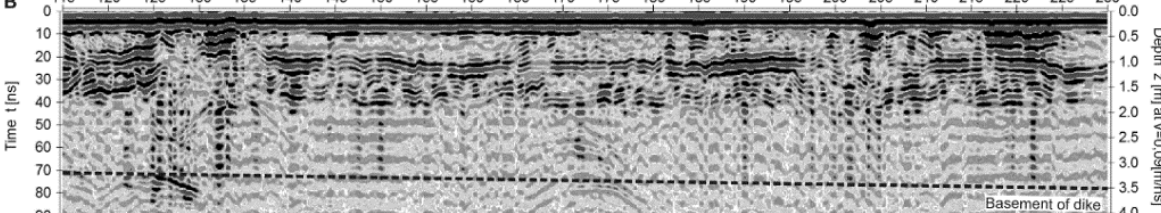

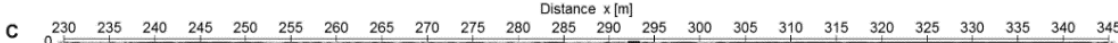

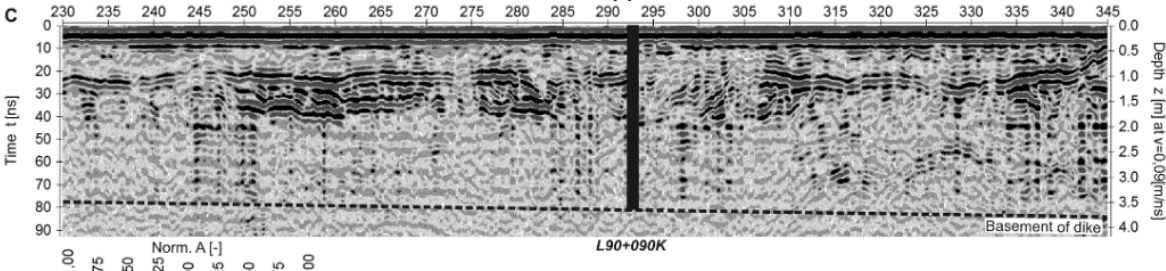

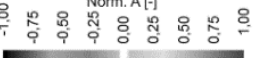

Fig. 7. Radargram for $250 \mathrm{MHz}$ antenna, stacking 4 times: A) profile from $\mathrm{x}=0 \mathrm{~m}$ to $115 \mathrm{~m}$; B) from $x=115 \mathrm{~m}$ to $230 \mathrm{~m}$; C) from $\mathrm{x}=230 \mathrm{~m}$ to $345 \mathrm{~m}$.

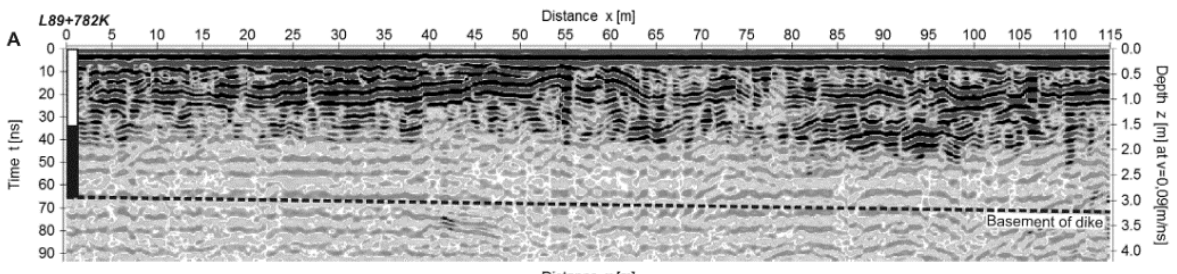

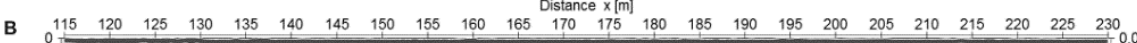

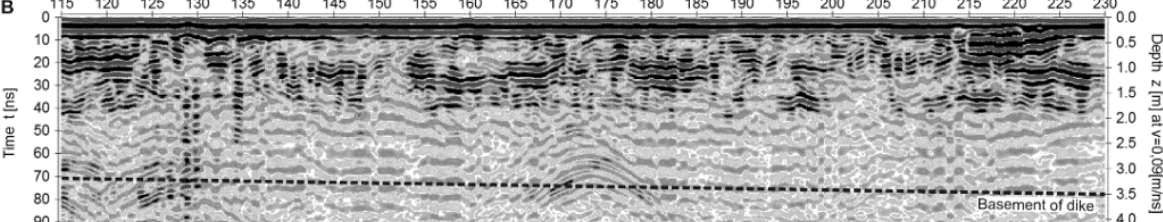

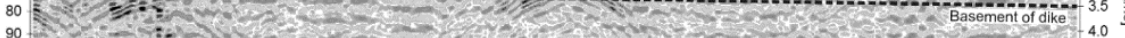

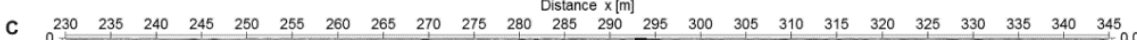

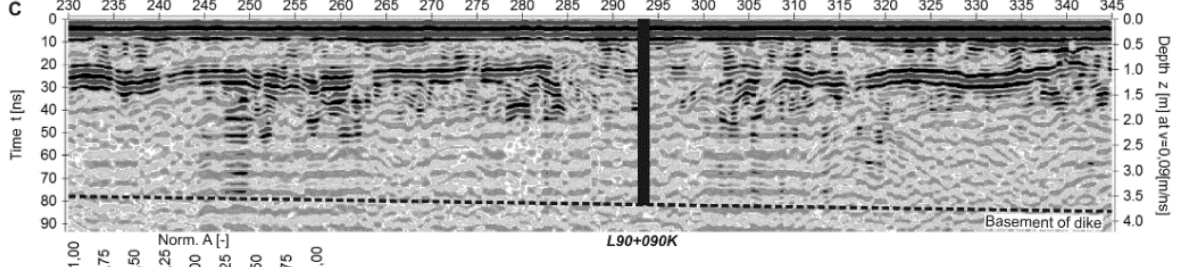

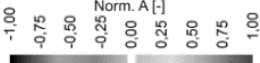

Fig. 8. Radargram for $250 \mathrm{MHz}$ antenna, stacking 32 times: A) profile from $\mathrm{x}=0 \mathrm{~m}$ to $115 \mathrm{~m}$; B) from $x=115 \mathrm{~m}$ to $230 \mathrm{~m}$; C) from $\mathrm{x}=230 \mathrm{~m}$ to $345 \mathrm{~m}$. 

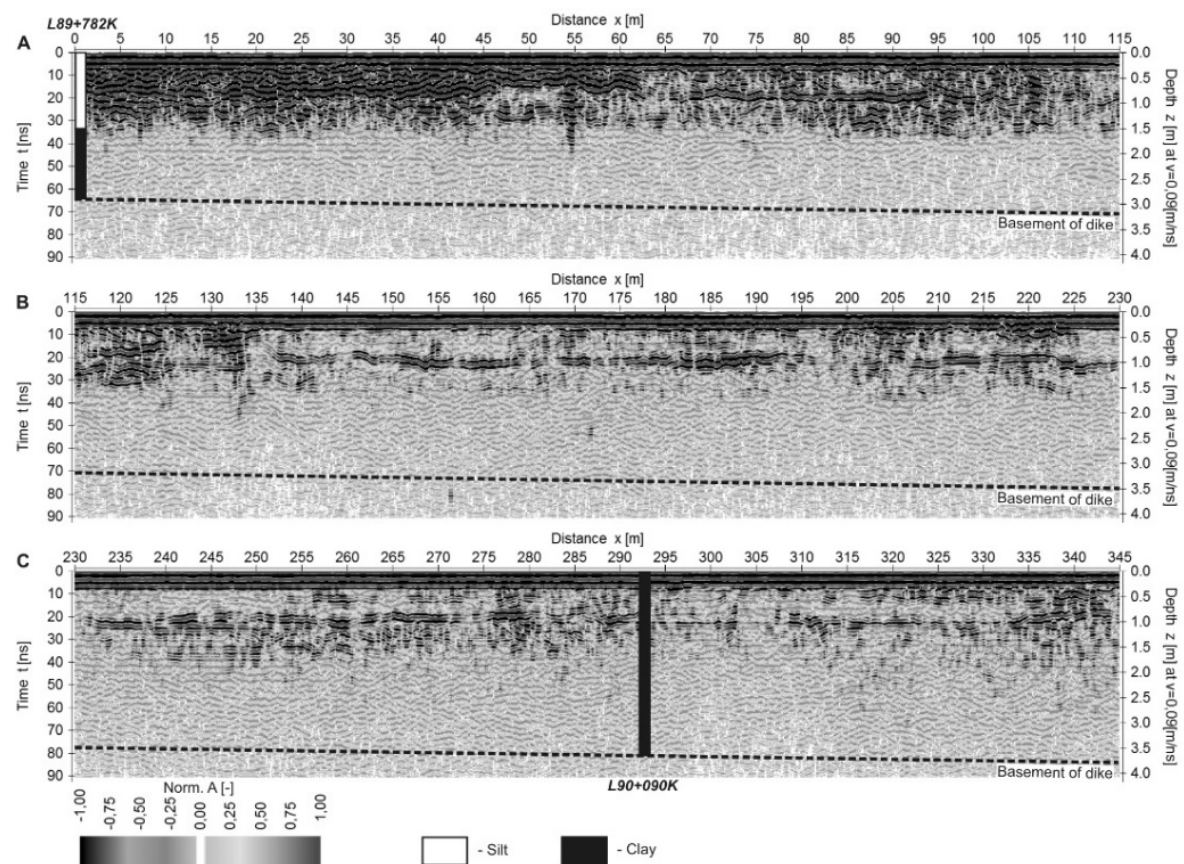

Fig. 9. Radargram for $500 \mathrm{MHz}$ antenna, stacking 4 times: A) profile from $\mathrm{x}=0 \mathrm{~m}$ to $115 \mathrm{~m}$; B) from $x=115 \mathrm{~m}$ to $230 \mathrm{~m}$; C) from $\mathrm{x}=230 \mathrm{~m}$ to $345 \mathrm{~m}$.
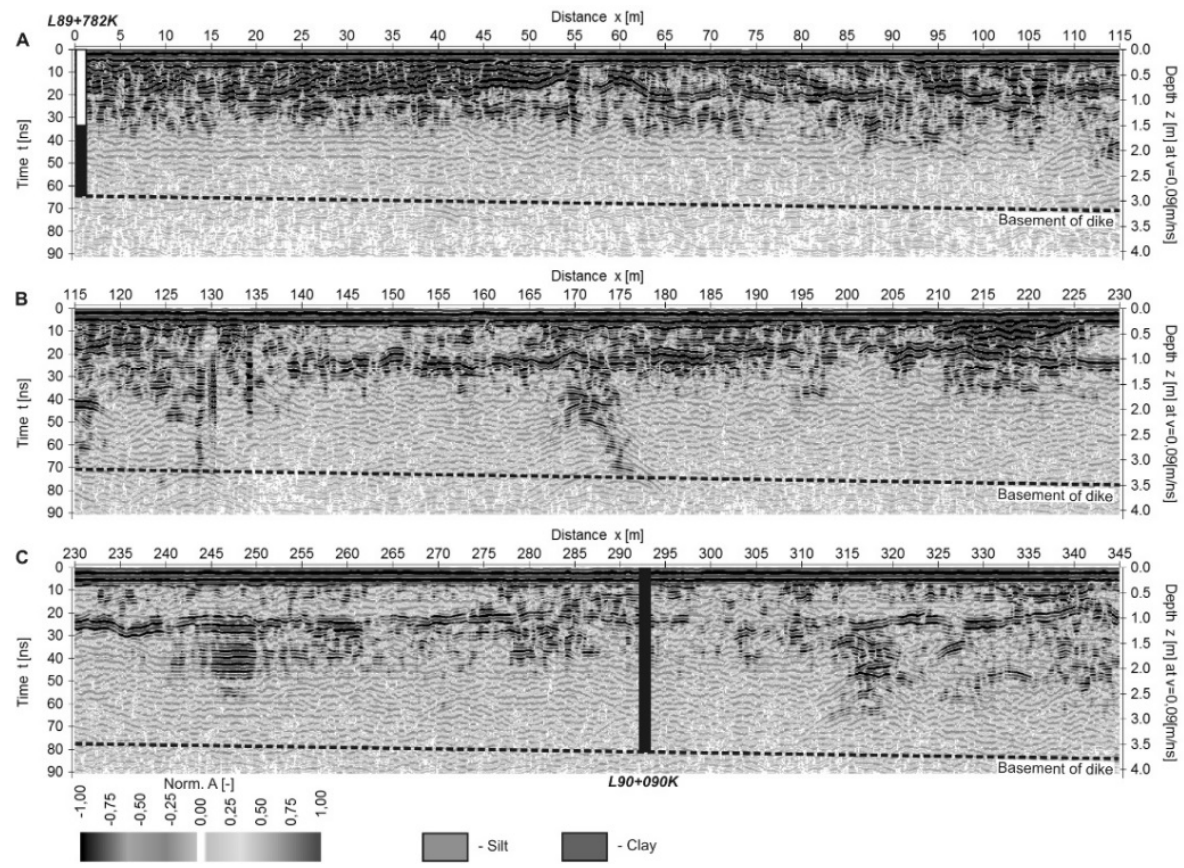

Fig. 10. Radargram for $500 \mathrm{MHz}$ antenna, stacking 32 times: A) profile from $\mathrm{x}=0 \mathrm{~m}$ to $115 \mathrm{~m}$; B) from $x=115 \mathrm{~m}$ to $230 \mathrm{~m}$; C) from $\mathrm{x}=230 \mathrm{~m}$ to $345 \mathrm{~m}$.

In the second stage of data processing, we combined radargrams, first for $250 \mathrm{MHz}$ antenna and second for $500 \mathrm{MHz}$ antenna. This was done to better distinguish the main disintegrated regions. The procedure involves overlaying two radargrams recorded for 
$250 \mathrm{MHz}$ antenna (Figs. 7 and 8) and two radargrams for $500 \mathrm{MHz}$ antenna (Figs. 9 and 10). Afterwards, more advanced processing was applied [12] to the composite radargrams, specifically the following processing procedures were used: spectral whitening, a gain function in the form of an energy decay procedure, bandpass time-dependent frequency instead of Butterworth filtering, morphologic filtering, muting of direct air and ground waves and, finally, conversion of radargrams to envelope distributions (instantaneous amplitudes were evaluated using a Hilbert transform). The resulting radargrams in the form of an envelope distribution (which is a measure of the signal energy distribution) are shown in Fig. 11B (for $250 \mathrm{MHz}$ antenna) an in Fig. 11C (for $500 \mathrm{MHz}$ antenna); additionally, in Fig.11, information about the microgravimetric anomalies is presented (Fig. 11A). In Figs. $11 \mathrm{~B}, \mathrm{C}$ depth axis was reduced to a depth $2 \mathrm{~m}$, because no important anomalies were recorded at greater depths (Figs. 7-10).
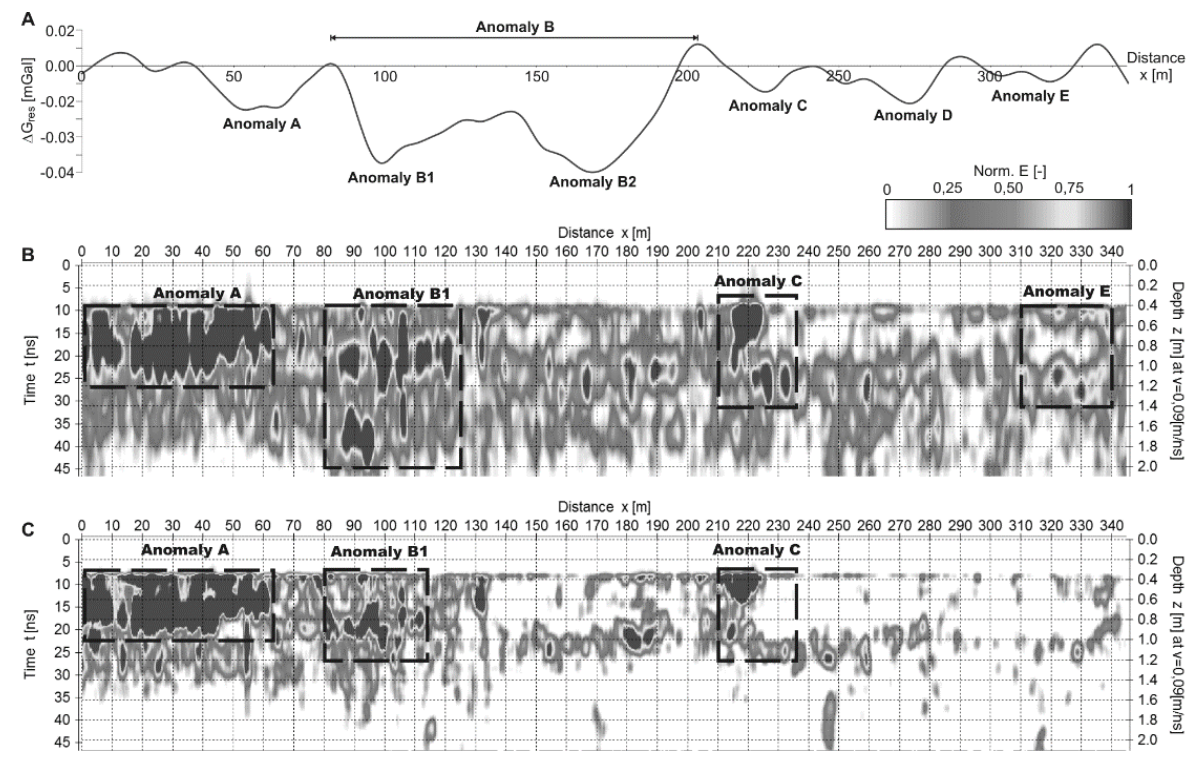

Fig. 11. A) Microgravimetric anomalies; B) Envelopes distribution for $250 \mathrm{MHz}$ antenna;

C) Envelopes distribution for $500 \mathrm{MHz}$ antenna.

In Fig. 11, it is evident that the GPR anomalies only partially correlate with the microgravimetric anomalies. A shifting of the anomalies along the profile direction is observed; this may be caused by inaccuracy of the distance measurement while using the wheel odometer in the GPR system on the slippery surface (mud and grass) of the crown; it is also possible that microgravimetric anomalies are shifted against GPR anomalies because the gravity meter records the total effect of unsymmetrical unconsolidated zones that may not be recorded in the $2 \mathrm{D}$ radargrams.

GPR anomaly B1 (Figs. 11 B, C) correlates well with microgravimetric anomaly B1 (Fig. 11A) so two geophysical methods allow us to depict first, big unconsolidated zone.

It is very strange that huge microgravimetric anomaly B2 (Fig. 11A) was not confirmed by the results of GPR surveys (Figs. $11 \mathrm{~B}, \mathrm{C}$ ); effect observed in the radargrams in gravimetric anomaly B2 should be similar to this recorded in anomaly B1 (Figs. 11 B, C)

Although, a general correlation is observed in the results of the two geophysical methods. Especially, anomalies A, B1, C and E are well-correlated (Fig. 11). The small amplitude of microgravimetric anomaly A (Fig. 11A) is puzzling since GPR recorded the strong, horizontal anomaly in this part of the examined levee (Figs. $11 \mathrm{~B}, \mathrm{C}$ ). 


\section{Gravity modelling}

In gravimetry, quantitative interpretation is often performed using gravity forward modelling [3]. $23 / 4 \mathrm{D}$ gravity modelling was applied to interpret the main anomaly "B". A model was created based on the available knowledge about the construction of the levee and the road crossing.

The modeling shows that the bulk density in the anomaly "B" area must have lower density relative to the rest of the levee by about $0.3 \mathrm{~g} \cdot \mathrm{cm}^{-3}$ (Fig. 12). These areas are located on both sides of the road and may be associated with the retention of rainwater snow and flood waters at the corner of the road and the levee. The "zero" density body is the remnant after the material has been compacted during road construction. The left side of the body corresponds to the right side of the GPR anomaly "B1". Additionally on both sides of the levee, there are other bodies that have been added to the gravity model at the location of the road crossing. Their densities were higher, at $\sim 0.15 \mathrm{~g} \cdot \mathrm{cm}^{-3}$, relative to the mean levee bulk density. It should be noted that during the gravity modelling it was assumed that the nearsurface layer (depths $<0.5 \mathrm{~m}$ ) has a constant mean bulk density along the entire length of the levee.

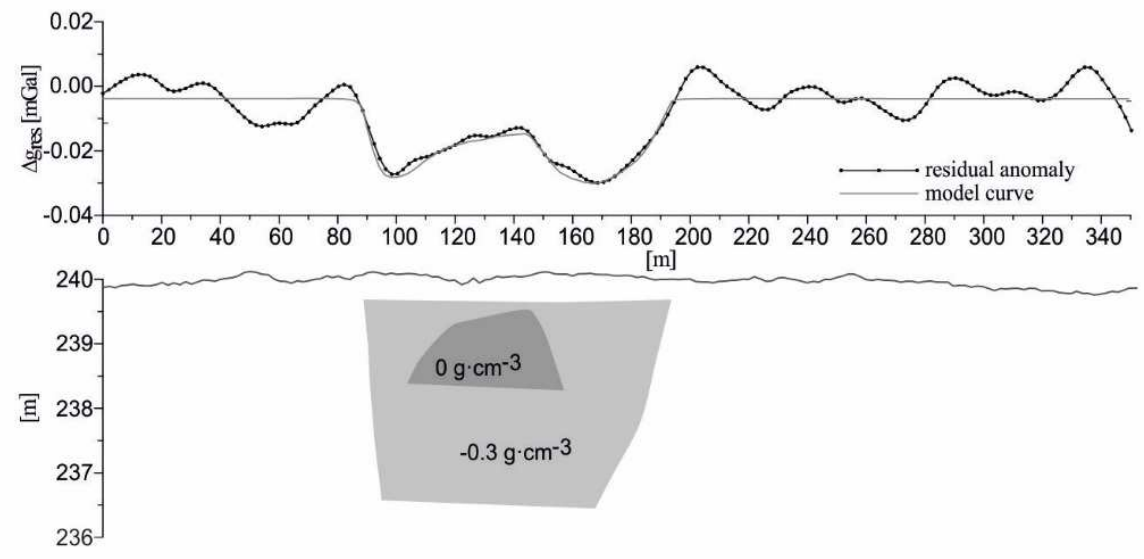

Fig. 12. The result of the gravity modelling of anomaly "B".

\section{Conclusions}

The results of the microgravimetric survey clearly demonstrate that this method can be applied to identify the potential weak zones in the levee. In described surveys several negative gravity anomalies with different amplitudes and horizontal extents are recorded. They can correspond to unconsolidated zones in levee structure. Nevertheless, they can be generated by a relatively higher content of non-cohesive soil (silt) in the levee.

The largest of the gravity anomalies was submitted to gravity forward modelling. The obtained density model unambiguously shows that within the profile section between 90 and $190 \mathrm{~m}$ the levee bulk density is significantly lower than at other places. This means that the levee may be susceptible there to failure during a flood.

As the levee consists of clay and silt, the GPR method allows to examine the body of levee only to depth c.a. $2 \mathrm{~m}$; therefore, correlation of the results obtained from the two geophysical methods was possible only in the near-surface zone. Hardly part of GPR anomalies were confirmed by microgravimetric surveys and vice versa. GPR method allowed to distinguish a boundary inside the levee, between either silt and clay or internal boundary 
in silt; this anomaly was not observed in microgravimetric data. Microgravimetric curve allowed to depict 6 anomalies, but only 4 was confirmed by GPR surveys.

An extensive suite of radarogram data processing has been performed, which allowed the better extraction of information about anomalies located in the near-surface area; some of GPR anomalies might be correlated with unconsolidated zones.

Short analysis, concerning the influence of stacking number to recorded data was also presented in the paper; higher stacking number not always results with better recordings.

The works were financed by a grant of AGH University of Science and Technology no. 11.11.140.645 and Grant of Cracow University of Technology, no. Ś-2/371/2018/DS.

\section{References}

1. A. Annan, Ground Penetrating Radar, Workshop notes, Sensor and Software, Canada (2001)

2. A. Mecke, I. Lee, J.R. Baker jr., M.M. Banaszak Holl, B.G. Orr, Eur. Phys. J. E 14, 7 (2004)

3. A. Cygal, M. Stefaniuk, A. Kret, M. Kurowska, Geology, Geophysics and Environment, 42, 3, 279-287 (2016), doi: 10.7494/geol.2016.42.3.279

4. T. Golebiowski, S. Porzucek, B. Pasierb, Near Surf. Geophys. 14, 4, 371-384 (2016), doi: 10.3997/1873-0604.2016017

5. G. Jonesa, P.Sentenaca, M. Zielinski, J Appl Geophys 106, 196-211 (2014), doi: 10.1016/j.jappgeo.2014.04.018

6. J. Karczewski, A. Lesniak, J. Zietek, T. Danek, Pol. J. Environ. Stud. 18, 3A, 142-148 (2009)

7. M. Loj, S. Porzucek, Science and Technologies in Geology, Exploration and Mining, SGEM 1, 743-749 (2015)

8. MALA 2004, Rules of thumb, MALA Geoscience AB, Mala, Sweden

9. MALA 2003, Basic and Advanced Radar Theory, MALA Geoscience AB, Mala, Sweden

10. E. Niederleithinger, A. Weller, R. Lewis, R. Stötzner, Conference: 4th International Symposium on Flood Defense, Toronto, Canada (2008)

11. S. Oryński, M. Okoń, W. Klityński, Acta Geophys. 64, 6, 2322-2336 (2016), doi:10.1515/acgeo-2016-0092

12. M. Di Prinzio, M. Bittelli, A. Castellarin, P. Rossi Pisa, J. Appl. Geophys. 71, 2-3, 5361 (2010) doi: 10.1016/j.jappgeo.2010.04.002 